\title{
Feitiço pega, uai? As práticas de magia no conto "São Marcos", de Guimarães Rosa
}

Carina Monteiro Dias ${ }^{1}$

https://orcid.org/0000-0001-5489-5469 http://lattes.cnpq.br/3011744251292452

João Claudio Arendt² http://lattes.cnpq.br/4108580744111952

Enviado em: 09/09/2018

Aceito em: 20/12/2018

\begin{abstract}
RESUMO: Por meio da análise do conto "São Marcos", da obra Sagarana, de Guimarães Rosa, objetiva-se refletir sobre o modo como a magia molda e constrói perspectivas de fé, crença e tabu na localidade de Calango-Frito, em cujo espaço social são compartilhadas diferentes percepções a respeito do crédito a simpatias e feitiçarias, consideradas aqui como ritos mágicos. Com o aporte teórico principal de Claude Lévi-Strauss (1970) e Marcel Mauss (2003), propõe-se que a magia está arraigada ao oculto e, por vezes, ao inexplicável, fazendo-se presente na cultura popular sertaneja como tradição repassada de gerações anteriores. De um modo geral, as práticas de magia inseridas em "São Marcos" têm papel significativamente social, servindo como recurso alternativo às necessidades mais diversas da comunidade representada por Guimarães Rosa.
\end{abstract}

Palavras-chave: Guimarães Rosa. "São Marcos”. Cultura popular. Magia.

ABSTRACT: Through the analysis of the short story "São Marcos", from the Sagarana work of Guimarães Rosa, the objective is to reflect on how magic shapes and constructs perspectives of faith, belief and taboo in the locality of Calango-Frito, in whose social space different perceptions are shared regarding the credit to sympathies and witchcraft, considered here as magical rites. With the main theoretical contribution of Claude Lévi-Strauss (1970) and Marcel Mauss (2003), it is proposed that magic is rooted in the occult and, sometimes, inexplicable, becoming present in popular culture sertaneja as tradition passed on generations. In general, the magic practices inserted in "São Marcos" play a significant social role, serving as an alternative resource to the most diverse needs of the community represented by Guimarães Rosa.

Keywords: Guimarães Rosa. "São Marcos". Popular Culture. Magic.

\section{Introdução}

Em Sagarana, Guimarães Rosa dá voz à cultura popular através de personagens que remetem ao universo sertanejo, com seus causos, estórias e provérbios entremeados ao enredo de cada conto. Conforme Teixeira (2017, p. 77), em análise da religiosidade na obra em referência, "as festas populares religiosas, os rituais, os benzedores e feiticeiros, as menções a Deus e aos santos formam um núcleo em torno do qual o enredo, as situações, o ambiente, os personagens orbitam, atraídos por força irresistível.” A cultura popular emerge

\footnotetext{
${ }^{1}$ Universidade de Caxias do Sul - UCS - Aluna do Programa de Pós-graduação em Letras e Cultura. Caxias do Sul. Email: cmdias1@ucs.br

2 Universidade de Caxias do Sul - UCS - Docente do Programa de Pós-graduação em Letras e Cultura. E-mail: joaoarendt@gmail.com
} 
da obra, nessa perspectiva, como resultado da transmissão oral do saber regional, ajudando a constituir uma memória e uma identidade coletiva para o sertanejo. Candido (2002) afirma que Sagarana não seria propriamente uma obra regionalista pela imersão em tais cenários e vivências, já que, através da figura do sertanejo, Guimarães Rosa exporia problemas universais enfrentados pelo homem, como amor, ódio, fé, entre outros.

Nesse sentido, em relação aos diversos fazeres e costumes regionais presentes em Sagarana, destacam-se, no conto "São Marcos", as práticas de magia. Compostas por simpatias, benzeduras e rezas, elas são compreendidas aqui como elementos da cultura popular e serão analisadas como ritos mágicos com base em conceitos oriundos das teorias desenvolvidas por Marcel Mauss (1872-1950) e Lévi-Strauss (1908-2009).

No conto em questão, João ou José ou Izé, narrador e protagonista, é extremamente crente, mas vive a zombar dos feiticeiros do Calango-Frito, em especial de João Mangolô. Por vezes, é até avisado de que tal atitude não terá boas consequências, o que não o impede de, sempre que possível, fazer troça com os feiticeiros.

Em uma de suas jornadas ao mato - local favorito para apreciar as variedades de plantas e animais existentes na região -, Izé encontra Aurísio Manquitola e recita, por zombaria, a oração de São Marcos, resultando em uma repreensão por banalizar uma prece tão poderosa. Ele também o adverte com casos passados de pessoas que enlouqueceram ao recitar tal oração.

Assim, certa vez, andando pelo mato, Izé é tomado por uma cegueira repentina e começa a se orientar pelos outros sentidos, especialmente a audição, o tato e o olfato. Desnorteado, entoa a oração de São Marcos e descobre estar próximo à casa de João Mangolô. Chegando lá, tenta estrangular o feiticeiro. E, quando retoma a visão, fica sabendo que o feiticeiro havia colocado uma venda nos olhos do seu retrato, para vingar-se das ofensas sofridas.

Os atos de magia descritos em "São Marcos" ocupam lugar de destaque no conto, já que são utilizados para os mais diversos fins como recurso auxiliar às necessidades físicas e espirituais da população de Calango-Frito. Mas o uso da magia exige do praticante, além de conhecimento e manipulação de diferentes elementos (rezas, componentes naturais, facas e pratos), a crença dele e do beneficiário da magia de que o ritual terá sucesso. Em um contexto onde não há presença marcante da igreja, percebe-se, em Calango-Frito, que a concepção de fé e de crença está alicerçada em um pilar distinto.

O imaginário religioso popular compõe-se pela distinção entre fé e crença. De acordo com Montero (1994), a ideia de fé está ligada a um Deus, em uma relação unilateral, sem negociação entre praticante e divindade. Tal concepção pode ser observada em igrejas e templos cujas práticas religiosas são tradicionais. Já a ideia de crença, carrega consigo a noção particular do indivíduo em torno de rituais e práticas que variam de acordo com o nível de confiabilidade despendida pelo indivíduo.

\section{Crenças populares locais: as "cismas" coletivas e individuais}

Logo no início do conto, o protagonista Izé descreve uma série de "cismas corriqueiras" partilhadas pelos habitantes de Calango-Frito, as quais ilustram como a comunidade organiza seu universo de crenças: 
[...] sal derramado; padre viajando com a gente no trem; não falar em raio; quando muito, e se o tempo está bom, "faísca"; nem pra dizer lepra; só o "mal"; passo de entrada com pé esquerdo; ave de pescoço pelado; risada renga de suindara; cachorro, bode e galo, pretos; e, principal, mulher feiosa, encontro sobre todos fatídico [...] (ROSA, 2015, p. 207).

As crenças populares, consideradas por Cascudo (1971) como superstições, são atitudes de defesa contra forças adversas do plano mágico: má-sorte, doenças, azar, atrasos na vida, entre outros. O termo superstição vem do latim "super-stitio, o que sobreviveu" (CASCUDO, 1971, p. 150), como perpetuação de cultos já desaparecidos. Parte dessas crenças reajustam-se com o passar do tempo, inserindo-se na sabedoria popular.

Todavia, há casos de crenças individuais que não são compartilhadas por todo o grupo social. No conto em questão, Izé, descrente dos feiticeiros locais, confessa trazer consigo objetos ou praticar diversos ritos individuais, como:

doze tabus de não-uso próprio; oito regrinhas ortodoxas preventivas; vinte péssimos presságios; dezesseis casos de batida obrigatória na madeira; dez outros exigindo a figa digital napolitana, mas da legítima, ocultando bem a cabeça do polegar; e cinco ou seis indicações de ritual mais complicado [...] (ROSA, 2015, p. 207).

Utilizados como ferramentas nas crenças populares, os referidos amuletos cumprem o papel de defesa para quem os carrega, impossibilitando que o indivíduo sofra qualquer dano. Por isso, Izé também trazia sempre consigo um amuleto "feito em meia-noite de sexta-feira da Paixão, que garantia invulnerabilidade à picada de ofídios" (ROSA, 2015, p. 207). O protagonista narra, a certa altura do conto, uma história antiga da região, vivenciada por Saturnino Pingapinga, na qual esse livrou-se de uma série de infortúnios por apenas trazer "a receita médica no bolso, só porque não tinha dinheiro para mandar aviar" (ROSA, 2015, p. 208). O amuleto, nesse caso, é comparado com a prescrição médica, como se ambos tivessem a mesma eficácia.

Mauss afirma que alguns amuletos não necessitam de preparações ritualísticas, como as pedras preciosas. Já para outros, há uma criteriosa organização de preceitos, como "se fazer à noite ou em horas escolhidas da noite, à meia-noite, por exemplo; outras, em certas horas do dia" (MAUSS, 2003, p. 82). No conto "São Marcos", há várias referências a práticas realizadas à meia-noite, indicando que tal horário é carregado de simbologia. Esse aspecto pode ser observado quando Izé fala dos porcos de Mangolô, que "à meia-noite, não convém a gente entrar aqui, porque todo porco nessa hora vira fera, e até fica querendo sair para estraçalhar o dono ou outro qualquer cidadão" (ROSA, 2015, p. 211).

Outros ritos que surgem no conto, como a prece feita por Sá Nhá Rita Preta, ao costurar a roupa vestida em Izé, dizendo "coso a roupa e não coso o corpo, coso um molambo que está roto...” (ROSA, 2015, p. 209), afastam o mau agouro. No caso da costura, segundo as crenças populares, só se cose roupa no corpo quando a pessoa está morta. Assim, as palavras proferidas Sá Nhá Rita Preta como proteção a Izé repelem a morte.

Segundo Candido (2002, p. 187), Guimarães Rosa edifica em Sagarana "um regionalismo muito mais autêntico e duradouro, porque criou uma experiência total em que o pitoresco e o exótico são animados pela graça de um movimento interior". Assim, as vivências do sertanejo narradas em "São Marcos", por exemplo, servem como pano de fundo para avivar situações e crenças não só regionais, mas de espectro bem mais amplo, abrangendo Deus, magia e fé, por exemplo. Ainda de acordo com Candido (2002, p. 185, grifo original), "Sagarana não vale apenas na medida em que nos traz um certo sabor regional, mas na 
medida em que constrói um certo sabor regional, isto é, em que transcende a região". As simpatias e feitiços, em "São Marcos", podem ser considerados ritos mágicos, já que, conforme Mauss (2003), a magia constitui um agente para alcançar um dado objetivo utilizando recursos físicos e não-físicos. O conjunto de ritos, simpáticos ou simbólicos, possui caráter mágico por viabilizar, por meio de cuidadosa elaboração, a possibilidade do desejado.

Izé apresenta, em sua narrativa, diversos casos em que ocorre a prática comum de magia na localidade, visto que "até os meninos faziam feitiço no Calango-Frito" (ROSA, 2015, p. 209). É o caso de Deolindinho, um menino de dez anos que criou um feitiço para vingarse de seu professor, o qual "dava muito coque, e batia de régua também" (ROSA, 2015, p. 209). Ele reuniu outros meninos que sofriam com esse problema e arquitetou o feito:

"Cada um fecha os olhos e apanha uma folha no bamburral" Pronto. "Agora, cada um verte água dentro da lata com as folhas!" Feito. "Agora, algum vai esconder a coisa debaixo da cama de Seu Professor!...” (ROSA, 2015, p. 209).

Percebe-se, nesse caso, que não há uma fórmula "pronta" de ingredientes utilizados e muito menos uma garantia de que o feitiço realmente funcione. Segundo Mauss (2003), as crianças comumente são utilizadas como ajudantes em práticas de magia e, inclusive, fazem rituais por conta própria. O mesmo autor acredita que a presença de crianças no ritual devase ao fato de elas ainda não terem sido submetidas às iniciações definitivas da sociedade. Por conseguinte, é possível afirmar que, nesse caso, não são os elementos utilizados que produzem o resultado esperado e, sim, a crença de que a magia funcionará. Deolindinho premedita o feitiço, mas deixa à mostra a ideia de que não há um roteiro pronto para o fim desejado.

Ainda assim, funcionou: ao deitar-se na cama, com o feitiço embaixo dela, o professor adoeceu. Conforme Izé, o mestre "quase morreu: só não o conseguiu porque, não tendo os garotos sabido escolher veículo inodoro, o bizarro composto, ao fim de um dia e meio, denunciou-se por si" (ROSA, 2015, p. 209). Deolindinho pode ser aqui considerado feiticeiro ou mágico, tanto porque ele é "o agente dos ritos mágicos, quer ele seja ou não um profissional” (MAUSS, 2003, p. 62), quanto porque a efetividade de sua magia é dada, entre outros aspectos, pela crença do menino na técnica utilizada.

Por conseguinte, Izé, cético em relação a tudo que se tratava por feitiçaria, era alertado por Sá Nhá Rita Preta, cozinheira da casa, para que não zombasse do desconhecido: "- Se o senhor não aceita, é rei ao seu; mas não abusar, não deve-de!” (ROSA, 2015, p. 208). Para elucidar seu alerta, Sá Nhá Rita narra o caso de uma lavadeira que sofreu repentinamente uma misteriosa dor nos pés e, ao esgotar todas as possibilidades da possível causa-raiz, lembrou "de desfeita que tinha feito para a Cesária velha" (ROSA, 2015, p. 209). Para Teixeira (2017, p. 33), “o intuito de Sá Nhá Rita, quando conta o caso da lavadeira, é ilustrar a veracidade do poder que os feitiços exercem em suas vítimas. Portanto, feitiçaria, para a personagem, é algo que se deve respeitar".

No conto não há a informação de que Cesária possuía poderes sobre-humanos, o que torna evidente a ideia de que a prática era utilizada como recurso alternativo para defesa e vingança. Sá Nhá Rita Preta continua o seus “causo”, contando que

[...] foi o tempo do embaixador chegar lá, para a dor sarar, assim de voo... Porque a Cesária tornou a tirar fora a agulha do pé do calunga de cera, que tinha feito, aos pouquinhos em sete voltas de meia-noite: "Estou fazendo fulana!... Estou fazendo fulana!...", e depois, com a agulha:

https://periodicos.unifap.br/index.php/letras

Macapá, v. 8, n. 3, $2^{\circ}$ sem., 2018 
“Estou espetando fulana!... Estou espetando fulana!...” (ROSA, 2015, p. 209).

Ao descrever a dor nos pés da lavadeira, Sá Nhá Rita Preta usa a expressão "lá dela", remetendo à hipótese de, assim, não reproduzir a dor em seus próprios pés. Isso porque existe na crença popular a ideia de que, quando se fala da dor de alguém em alguma parte do corpo, deve-se dizer sempre "lá nele", ou "lá nela", para não atrair a mesma dor sobre si.

Todas as representações de magia, de acordo com Mauss (2003), são fatos de tradição perpetuados pela repetição. A tradição é controlada pela experiência que põe continuamente à prova a vivacidade das crenças: o que não é repetido não se torna tradição e é logo esquecido.

Já os indivíduos voltados à magia não fazem parte de uma classe social especial devido a sua condição. É o que se vê no caso de João Mangolô, feiticeiro de Calango-Frito, descrito por Izé como:

[...] velho-de-guerra, voluntário do mato nos tempos do Paraguai, remanescente do "ano da fumaça", liturgista ilegal e orixá-pai de todos os metapsíquicos por-perto, da serra e da grota, e mestre em artes de despacho, atraso, telequinese, vidro moído, vuduísmo, amarramento e desamarração (ROSA, 2015, p. 208).

Izé prenuncia um triste fim para Mangolô, ao afirmar que "os feiticeiros sempre acabam mal" (ROSA, 2015 p. 211). Também imputa ao feiticeiro uma identidade, indicando que ele atuaria em diferentes áreas, fato que, no decorrer do conto, no entanto, não se confirma. Mauss atribui aos mágicos sagacidade e sabedoria pouco comuns:

Uma teoria simplista da magia poderia especular sobre sua inteligência e sua malícia, para explicar todo o seu aparato através de invenções e de embustes. Mas essas qualidades reais que continuamos a atribuir por hipótese ao mágico fazem parte de sua imagem tradicional, na qual vemos entrar muitos outros traços, que serviram de maneira diferente para fundar seu crédito (MAUSS, 2003, p. 69).

Esses traços míticos são resultados da transmissão oral de feitos e estórias que se apresentam em geral na forma de lendas ou mitos, ocupando um lugar considerável na cultura popular como parte do imaginário coletivo. Em suma, a crença é real, na medida em que é partilhada por todos do grupo, pois "a magia é acreditada e não percebida" (MAUSS, 2003, p. 131). Além disso, cada parte envolvida tem grande importância para que ocorra o esperado.

\section{O tabu em torno da oração de São Marcos}

Entre as diversas práticas e ritos já mencionados, é interessante observar o modo como a oração de São Marcos, santo que dá título ao conto, é temida e respeitada pelos personagens, com exceção de Izé. Como já se mencionou, em uma de suas incursões à mata, o narrador encontra Aurísio Manquitola e faz graça e insinua que ele vinha da casa do feiticeiro João Mangolô. Aurísio repele-o dizendo: "Tesconjuro!... Tou vindo mas é da missa [...]” (ROSA, 2015, p. 212). Izé insiste na brincadeira e dá a entender que Aurísio tem medo de Mangolô e de sua feitiçaria. Aurísio retruca: 
[...] Há-de-o!... Agora, abusar e arrastar mala, não faço. Não faço porque não paga a pena... De primeiro, quando eu era moço, isso sim!... Já fui gente!, gente. Para ganhar aposta, já fui, de noite, foras d'hora, em cemitério... Acontecer, nunca me aconteceu nada; mas essas coisas são assim para rapaz. Quando a gente é novo, gosta de fazer bonito, gosta de comparecer. Hoje, não: estou percurando é sossego... (ROSA, 2015, p. 212).

Ao mencionar as aventuras passadas, Aurísio deixa claro que, quando jovem, não pensava nas consequências de seus atos, e que tudo que era ligado ao mistério e ao desafio tornava-se interessante para ele. Agora, com a passagem dos anos, procura sossego, do que se depreende que a sua concepção de magia e mistério mudou, preferindo não mais adentrar em tais assuntos.

$\mathrm{Na}$ sequência do conto, enquanto conversam e comem laranjas, Aurísio mostra a foice que utiliza para cortar as frutas e exalta o objeto por ter maior eficácia, do que armas de fogo e facas. Segundo ele, "para foice não tem nem reza, moço" (ROSA, 2015, p. 212). Izé, atrevidamente, questiona se a foice teria a mesma eficácia de rezas como "sete ave-marias retornadas" ou "São Marcos". Ao ouvir Izé mencionar a oração de São Marcos, Aurísio exalta-se:

- Pára, creio-em-deus-padre! Isso é reza brava, e o senhor não sabe com o que está bulindo!... É melhor esquecer as palavras... Não benze pólvora com tição de fogo! Não brinca de fazer cócega debaixo de saia de mulher séria!... (ROSA, 2015, p. 212).

A referida oração teria poderosas consequências desconhecidos por Izé, que confessa, ao cabo, tê-la guardado apenas por achá-la engraçada. De acordo com Mauss (2003), incluem-se como magia as mais variadas formas orais presentes na religião, como preces, votos, orações e rezas, consideradas ritos orais. Genericamente, são elas associadas a encantamentos e possuem estruturas rituais específicas.

No conto, Aurísio continua advertindo Izé de que "só por a gente saber de cor, ela já dá muita desordem" (ROSA, 2015, p. 213), revelando o tabu que repousa sobre a perigosa oração. Os tabus abrangem, segundo Freud (2006), um caráter sagrado ou proibido de algo ou alguém, de forma distinta às proibições religiosas ou morais de dada sociedade. Ainda conforme o pensamento de Freud, pode-se afirmar que os tabus criados em cada cultura não seguirão necessariamente uma ordem divina, ou terão sua origem conhecida.

No conto em análise, as consequências sofridas por quem profere uma oração proibida destacam-se no curioso caso de Gestal da Gaita, que "sabia a tal e rezava quando queria..." (ROSA, 2015, p. 213). Um dia, o compadre de Aurísio, Silivério das Araras, teve de pernoitar na casa de Gestal, sendo surpreendido a altas horas da noite totalmente transtornado, apresentando comportamento incomum:

- O senhor vá escutando: o que houve foi que o meu compadre Silivério, que já estava meio arisco, dormindo com um olho só e outro não, viu o cabra vir pra ele, de faca rompente, rosnando conversa em língua estranja... Foi o tempo de meu compadre Silivério destorcer da caxerenguengue e pular fora do jirau: ainda viu o outro subindo parede arriba, de pé em-pé! Aí o homem acordou, quando bateu com a cabeça nos caibros, parece-que, e despencou de lá, estrondando... Fez um galo na creca, por prova, mas negou e negou que tinha subido em parede, perguntando ao meu compadre se ele não era que não tinha sofria de pesadelo... Ara! Ara! Pra ver gente sonhar nesse esquerdo, ah eu fora de lá!... (ROSA, 2015, p. 213).

A continuação da crença em determinado tabu consiste, na visão de Mauss (2003), na

https://periodicos.unifap.br/index.php/letras

Macapá, v. 8, n. 3, $2^{\circ}$ sem., 2018 
sua não-violação. Quando não há questionamento sobre a sua veracidade, ele perpetua-se. A sociedade é que instaura e legitima o que é certo, proibido ou sagrado.

Por sua vez, Tião Franjão, "aquele meio leso, groteiro do Cala-a-boca, que vem vender peixe-de-rio no arraial” (ROSA, 2015, p. 213), também criara muitos problemas ao recitar a oração de São Marcos. Traído pela mulher e alvo de injúrias, foi ajudado por Gestal da Gaita, que o ensinou a recitá-la "para ajuda de ele ter alguma valença nos apertos" (ROSA, 2015, p. 213). Após a vida de Tião dar mil voltas, em uma delas acaba por ser preso acusado de matar um homem:

Bom, eles trancaram o Tião. De certo que eles bateram também no Tião. Mas, e depois? seu moço?!... Ele deve ter rezado a reza à meia-noite, da feição que o diabo pede, o senhor não acha? Pois, do contrário, me conte: quem foi que deu fuga ao preso, das grades, e carregou o cujo de volta para casa - quatro léguas, que, de-madrugadinha, estava ele chegando lá, e depois na casa do outro, e entrando guerreiro e fazendo o pau desdar, na mulher, no carapina, nos trastes, nas panelas, em tudo quanto há?!... [...] Foi precisão de umas dez pessoas, para sujeitar o Tião, e se a gente não tonteasse o pobre... (ROSA, 2015, p. 216).

Voltando à concepção de magia, Aurísio adverte Izé de que a oração de São Marcos, "para fazer bom efeito, tem que ser rezada à meia-noite, com um prato-fundo cheio de cachaça e uma faca nova em folha, que a gente espeta em tábua de mesa" (ROSA, 2015, p. 213). Sobre a eficácia do rito mágico, Lévi-Strauss apresenta três aspectos: a convicção do próprio feiticeiro em sua técnica, a crença do beneficiário da magia e a aprovação da opinião coletiva, sendo a "situação mágica um fenômeno de consensus" (LÉVI-STRAUSS, 1970, p. 185, grifo original).

No conto, quando Izé fica repentinamente cego, em uma de suas incursões na mata, seus sentidos e crenças são colocados à prova. Em meio à raiva e ao cansaço, como gesto de última esperança, ele profere a reza de São Marcos. Tomado, então, por revigoramento incomum, consegue localizar-se na escuridão, ao escutar o grunhido de porcos, dando-se conta que estava próximo da cafua de Mangolô. Ao entrar de súbito na casa e questionar se o feiticeiro fora o responsável pelo mal sofrido, esse defende-se, alegando:

- Não quis matar, não quis ofender... amarrei só esta tirinha de pano preto nas vistas do retrato, p'ra Sinhô passa uns tempos sem poder enxergar... Olho que deve de ficar fechado, p'ra não precisar de ver negro feio... (ROSA, 2015, p. 230).

Em conformidade com Roncari (2000, p. 88), o conto "São Marcos é o relato de uma possessão, de um homem urbano que provoca e desafia os poderes mágicos dos feiticeiros e das rezas dos homens do Calango-Frito, onde ele se situa como um estranho no lugar". Coincidência ou não, Izé proferiu a oração, Mangolô retirou a faixa de pano, e a visão voltou ao normal.

Não cabe aqui discutir sobre qual foi a verdadeira solução para o caso, mas, sim, perceber que a magia, enquanto fenômeno social, indiferentemente da forma de seus ritos, é produzida e marca seu lugar no conjunto das práticas sociais regionais.

\section{Considerações Finais}

O crítico literário Álvaro Lins (1946), no ano de estréia de Sagarana, anunciou que a obra como um todo representa aspectos físicos, psicológicos e sociais de um grupo social 
do interior de Minas Gerais. Embora sejam ficção, tais enredos ultrapassam as esferas regionais, explicitando em cada conto o espírito dos dilemas humanos

Assim, no que diz respeito às ideias de fé e crença em "São Marcos", é importante observar, ainda, que não há menção sobre a presença de igrejas ou templos, subentendendo-se que a construção do oculto ou do sagrado dá-se pelo respeito às

tradições repassadas pelas gerações anteriores. Cada comunidade ou sociedade possui seus próprios padrões morais e de conduta, de modo que a fé, os tabus e as crenças variam de uma para outra, podendo se constituir pela tradição oficializada ou não por instituições.

Em linhas gerais, a prática de magia, com seus ritos e crenças, mostra-se um recurso importante à população de Calango-Frito como forma de significar, avaliar e intervir na realidade. Sem ela, a vida da comunidade seria completamente diversa e, talvez, nem fizesse sentido. Daí a importância de olhar para o tema com olhos menos judicativos e mais compreensivos, como o fez Guimarães Rosa no conto "São Marcos". Nessa perspectiva, segundo Teixeira (2017, p. 37), a cegueira temporária de Izé remete à "falta de visão dos privilegiados de um grupo social que, ao se depararem com os indivíduos que não se coadunam com seus ideais de cultura, rechaçam o que não reflete a sua própria imagem."

\section{Referências}

CANDIDO, A. Textos de intervenção. 1 ed. São Paulo: Livraria Duas Cidades, 2002.

CASCUDO, L. C. Tradição, Ciência do Povo. São Paulo: Perspectiva S. A, 1971.

CASCUDO, L. C. Civilização e Cultura. Volume II. Rio de Janeiro: José Olympio Editora, 1973.

FREUD, S. Totem e Tabu e outros trabalhos (1913-1914). Volume XIII. Rio de Janeiro: Imago, 2006.

LÉVI-STRAUSS, C. Antropologia estrutural. 2 ed. Rio de Janeiro: Tempo Brasileiro, 1970. LINS, A. Jornal de Critica: Uma grande estreia. Correio da manhã. Rio de Janeiro, 12 de Abril de 1946, ed. 15779. p. 2. Disponível em: http://memoria.bn.br/DocReader/DocReader.aspx?bib=089842_05\&PagFis=31981. Acesso em 12 Mar 2018.

MAUSS, M. Sociologia e antropologia. São Paulo: Cosacnaify, 2003.

MONTERO, P. Magia, racionalidade e sujeitos políticos. Revista Brasileira de Ciências Sociais, on-line, São Paulo, v.9, n.26, Outubro, 1994. Disponível em: http://www.anpocs.org.br/portal/publicacoes/rbcs_00_26/rbcs26_06.htm. Acesso em 3 Jan 2018.

RONCARI, L. O engasgo de Rosa e a confirmação milagrosa. Revista Remate de Males, online, Campinas, v. 20, n.1, 2000. Disponível em: https://periodicos.sbu.unicamp.br/ojs/index.php/remate/article/view/8636149. Acesso em 12 Mar 2018.

ROSA, J. G. Sagarana. Edição especial. Rio de Janeiro: Nova Fronteira, 2015.

TEIXEIRA, J. Graças a Deus, tudo é mistério. A religiosidade como regionalidade em Sagarana, de Guimarães Rosa. Dissertação de Mestrado, Programa de Pós-graduação em Letras, Cultura e Regionalidade. Universidade de Caxias do Sul, 2017. 